\title{
Editorial
}

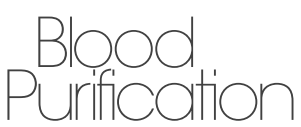

Blood Purif 2004;22(suppl 1):1-30

DOI: $10.1159 / 000079187$

\section{Dear Friends;}

The 9th annual conference of the Japanese Society for Hemodiafiltration in conjunction with International Symposium on Hemodiafiltration was held in August 2003, in Kamakura, Japan. It is my great pleasure to send you English version of the abstract book of the meeting translated from original Japanese transcripts (except for those originally written in English).

According to annual statistics published by the Japanese Society for Dialysis Therapy, the total number of end-stage renal disease (ESRD) patients has been linearly increasing in Japan over the past 20 years. It is also apparent that clinical outcomes of Japanese dialysis therapy are better than those of other industrialized nations. Nevertheless, an increase in number of patients has induced an increase in the number of clinics, dialysis machines and medical staff, resulting that the total medical expenses for the treatment of ESRD patients have already exceeded 1 trillion yen (approx. 10 billion US\$). Much high-tech equipment and many devices have been developed over the last 30 years; however, the UF controller and RO water treatment system that have widely been used in most clinics may be unusual exceptions because many others are not in use or are used only for a small number of patients. Regretfully, although hemodiafiltration (HDF) has a higher efficiency for removing toxic substances, it is used only for a limited number of patients.

The first academic meeting of the Japanese Society for Hemodiafiltration (JS-HDF) was held in Tokyo in 1995, whereas the first board meeting was held in 1994 after the very first Kyushu preparatory meeting in 1993; therefore the 9th meeting in 2003 became the 10th anniversary of the first meeting. The main theme of the 9 th conference was 'HDF of the people, by the people, for the people', which was taken from the famous Gettysburg Address by Abraham Lincoln, the 16th president of the United States. Lincoln said, 'Government of the people, by the people, for the people should not perish from the earth.' We must now say, 'HDF of the people (national population), by the people (staff at medical companies \& clinics), for the people (patients) should not perish from medicine', because the number of HDF patients has not been increasing over the last ten years. We invited some European HDF experts; in particular, Dr. Nguyen K. Man, one of the greatest scientists on HD therapy since the 70 's, presented the Keynote Lecture in

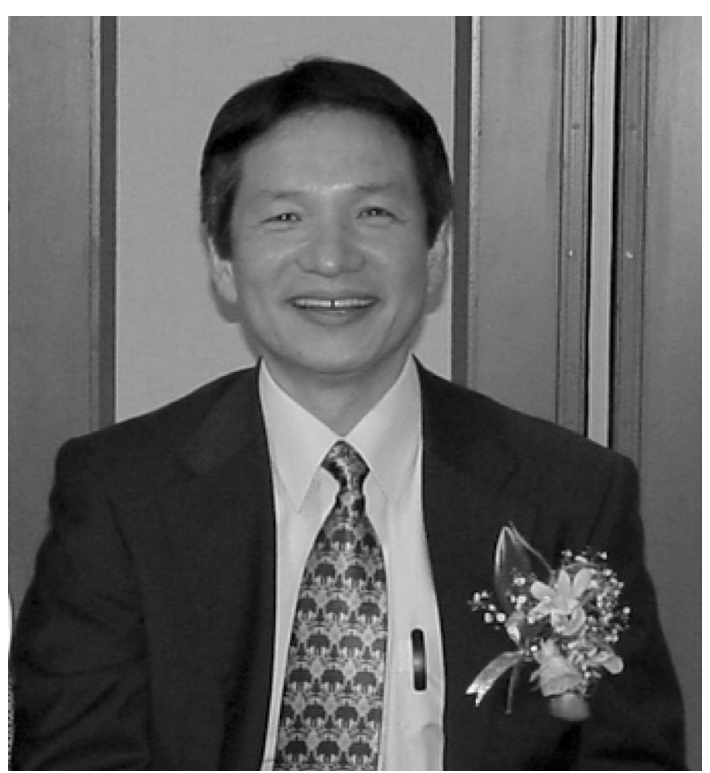

which he summarized the controversies surrounding HDF treatment.

It is stated ' ... above all, we are aiming to establish an academic background to on-line HDF and push \& pull HDF and to make these treatments popular' in the regulation of society. Along with this statement, we first proposed a guideline for water purification which is now becoming a common practice for medical staff dealing with on-line treatments. This year, our guideline based solely on endotoxin concentration in dialysate was discussed from the clinical outcome point of view in the symposium (Day 1). The next step is consideration as to whether the most powerful treatment is the best treatment or not. European HDF experts discussed all the strong and weak points of HDF therapy during the four international debate sessions (Day 2). All four topics were classical yet still controversial. It was difficult to conclude which was better than the other; however, participants enjoyed a perspective of HDF as well as some skilful presentations. We also had four introductory seminars by Japanese experts. As all four topics have recently been re-evaluated specifically for HDF treatment, participants should find something new from the seminar (Day 1, 2). In the two sessions of 'industry speaks', all six speakers, responsible for their dialysis business, summarized 'company policy and profits' (Day 1,2).

\section{KARGER}

Fax +41613061234

E-Mail karger@karger.ch

www.karger.com 
Under some specific circumstances, the company's policy may come first and profits second, making 'when?' the key question during these sessions. Luncheon seminars planned by six leading Japanese dialysis-related companies were also well organized and of high interest.

In addition, daily hemofiltration, a novel treatment modality involving large amounts of fluid exchange, was discussed at the very beginning of the conference, demonstrating some clinical and theoretical results. All other new ideas and clinical results were presented during the oral session with PC presentation.

In total, there were 79 papers (39 special sessions and 40 oral sessions), a larger number than any previous JS-HDF conference. This may imply that HDF is now becoming popular or that more medical staffs are interested in water purification systems. On behalf of the organizing committee, I would express my sincere gratitude not only to those published papers but also to those attended the conference. I hope this conference presented some useful hints for treatments and/or future research and also gave a splendid opportunity for extending personal friendship among the participants.

We are also planning to publish a book entitled 'Trends on Hemodiafiltration' based on selected papers published in the Kamakura meeting. Please advise us if you are interested in the forthcoming book that includes scientific and exciting papers on current topics of HDF therapy.

Best regards,

Akihiro C. Yamashita, Ph.D.

President, 9th Annual Conference of the Japanese Society for Hemodiafiltration in conjunction with the International Symposium on Hemodiafiltration Therapy

Professor, Department of Materials Science \& Engineering Shonan Institute of Technology

Kanagawa, Japan 